\title{
Ranking of Everyday Activities by Risk of Coronavirus in the Istanbul Metropolitan Area, Turkey
}

\author{
Umit Kartoglu', [MD] \\ ORCID: 0000-0003-0868-0007 \\ Deniz Nala Kartoglu ${ }^{2}$ \\ ORCID: 0000-0001-7213-9560 \\ Levent Eker', [MD] \\ ORCID: 0000-0001-7301-4073 \\ Hamza Ozdemir4, [MD] \\ ORCID: 0000-0003-3682-0134 \\ Nilufer Ayse Ozaydin 5 , [MD] \\ ORCID: 0000-0002-2616-0710
}

'President and CEO, Extensio et Progressio, $1 \mathrm{~A}$ chemin du Pre-d'Orsat, 1245 Collonge-Bellerive, Switzerland.

2University of Geneva, Faculty of Psychology and Educational Sciences, Geneva, Switzerland.

${ }^{3}$ Eastern Mediterranean University, Faculty of Health Sciences, Department of Physiotherapy and Rehabilitation, Famagusta, Northern Cyprus.

${ }^{4}$ Hurriyet Family Health Centre, Kagithane, Istanbul, Turkey.

${ }^{5}$ Marmara University, Faculty of Medicine, Department of Public Health, Istanbul, Turkey.

Corresponding Author: Umit Kartoglu

President and CEO, Extensio et Progressio, $1 \mathrm{~A}$ chemin du Pre-d'Orsat, 1245 Collonge-Bellerive, Switzerland. E-mail: umit@kartoglu.ch

https://doi.org/10.32552/2021.ActaMedica.583

\section{n ABSTRACT Con}

Objective: Understanding how people evaluate and perceive risks is critical in designing successful risk communication strategies. Very limited information is available in Turkey regarding how people determine whether something is risky or safe. The purpose of the study was to document the ranking of everyday activities by risk of coronavirus by health professionals and others. Besides analyzing the risk ranking differences between these two groups, creating an infographic based on the rankings of health professionals was the main objective.

Materials and Methods: An online descriptive study was planned to understand how health professionals and non-health professionals rank the risks of 43 everyday activities from a COVID-19 perspective in the Istanbul metropolitan area. The study hyperlink was shared through social media channels, as well as professional associations targeting health professionals. Responses were analyzed in SPSS.11. The statistical significance level was accepted as $p<0.05$.

Results: We received 1,614 valid responses through online submissions, of which $738(45.7 \%)$ were health professionals, and 876 (\%54.3) were from non-health sectors. Mask use and the respect of the $1.5 \mathrm{~m}$ distance from others were found to be similar in participants from health and non-health sectors. Hand washing and the use of hand sanitizers were found to be significantly higher among health professionals. Health professionals, women, and participants with higher education ranked the risk of everyday activities higher than other groups. The activities that were ranked as high-risk share some common features like closed spaces, crowded places, and activities that require people to be close to each other and, in some cases, touching.

Conclusion: Based on the rankings of the 738 health professionals, an infographic illustrating the ranking scores of the 43 everyday activities, both through labels and colors, was developed, using a cartoon-style Istanbul metropolitan landscape.

Keywords: Risk ranking, coronavirus, COVID-19, infographic, Istanbul 


\section{INTRODUCTION}

With the first cases from Wuhan, China officially reported on the 31st of December 2019, the new SARS-CoV-2 epidemic soon turned global. It was declared a pandemic by the World Health Organization (WHO) in March 2020 [1-3]. In the absence of a specific treatment and an effective vaccine, government responses ranged from physical distancing, hand-hygiene advice, and the use of masks, to non-pharmaceutical measures including closing schools, stay-at-home policies or lockdown among others [4]. Testing, isolating cases contact tracing, along with other public health measures, helped to slow down the spread and suppressed the peak, thus providing the muchneeded time for health systems to better their response [5-8].

The impact of the COVID-19 pandemic proved that it was far more than a health crisis. It affected every country's society and economy at varying degrees. Despite WHO's warnings in April, when daily new cases began to decrease, countries started to lift restrictions even if they did not meet the WHOdefined criteria for doing so - for economic reasons $[9,10]$. As a result, cases started to soar and even reached levels higher than the first wave. There are now more than 173 million cases and 3.7 million deaths reported globally [11].

The first case of COVID-19 in Turkey was confirmed on the 11 th of March 2020 by the Ministry of Health $(\mathrm{MoH})$ [12]. By the 7th of June 2021, Turkey had reported more than 5.2 million cases and 48,000 deaths [13]. The management of the pandemic by the $\mathrm{MoH}$ in Turkey has been heavily criticized by the Turkish Medical Association and other medical professionals - that the figures reported by the authorities do not reflect reality $[14,15]$. The messages given by the ministerial authorities were also found to be unclear, confusing and thus contributing to the relaxation of the population in adherence to protective measures. Although authorities did not reveal regular information on the location or details of the cases, it was implied that Istanbul, the biggest metropolitan area in Turkey, was the centre of the epidemic [16].

People evaluate risks with the information they have, often times under uncertainty [17]. Considering what is known, along with the likelihood of different consequences, people reach a judgment on whether the event is risky or not [1820]. Studies have shown that factors such as gender, race, political worldview, commitment, emotional impact, and trust are associated with risk judgment [21-24]. Our mental models of risk and our trust in the sources that communicate risk-related issues affect how we interpret risk communication [25].

There are several examples of the ranking of risky activities related to the potential transmission of COVID-19. This information is usually represented either in table format or in a bar/bubble graph with color coding, ranging usually from green (low risk) to red (high risk). Some use icons in reference to activities to add visuals to these representations. The Texas Medical Association COVID-19 Task Force and Committee on Infectious Diseases produced a bar chart, ranking activities by risk level from getting restaurant takeout (low) to visiting an elderly relative or friend in their home (moderate), to going to a bar (high), on a scale of 1 to 10 [26]. The COVID-19 risk index put together by Dr. E. Emmanuel, Dr. J. Phillips, and S. Papescu is the most visual index produced, making use of icons, color coding, and varying box sizes to reflect the degree of risk [27].

In Turkey, the first coronavirus-related risk perception survey was conducted during the very early stages of the pandemic, with $12 \%$ of participants mentioning that they do not take any precautions at all, and $22 \%$ that they do not hesitate to go anywhere [28]. Another survey was conducted to determine the health anxiety levels and the perception of control of COVID-19 in Turkey [29]. In June of 2020, the Social Sciences Board of the MoH (Turkey) indicated that they would measure the public perception of the coronavirus, but there has been no further news [30].

This study aims to understand how health professionals and non-health professionals rank the risk of everyday activities from a COVID-19 perspective in the Istanbul metropolitan area.

\section{OBJECTIVES}

The purpose of the study was to document the risk ranking of everyday activities from a COVID-19 perspective by health professionals and others. 
In line with the purpose, more specific objectives were defined below:

- To analyze whether there is any significant difference in the risk ranking of everyday activities by health professionals and others.

- To analyze whether there is any significant difference in the risk ranking of everyday activities by gender, education level, and age.

- To produce an infographic based on the risk ranking done by health professionals as a communication tool for the general public.

\section{MATERIALS and METHODS}

Since risk ranking involves risk perception, we decided to conduct the survey in one geographical area (Istanbul metropolitan) to limit the impact of different local epidemiological situations on risk perception. This was so that participants would not rank with a big variation due to being from different parts of the country with varying risks. The ranking was done on an online survey developed on Survey Monkey.

The survey link was distributed on social media platforms as well as through formal networks at medical faculties and professional medical societies in Istanbul. The survey link was kept open for the month of August 2020.

The survey used for this descriptive study contained a total of 17 questions about personal information, current behaviors in regard to facemask use, physical distancing, handwashing and the use of disinfectant solutions, followed by a list of 43 daily activities to be ranked from 1 (low) to 5 (high).

The study was approved by the ethical board of Marmara University, Istanbul (24th of July 2020, protocol code 09.2020.926).

At the beginning of the survey, all the participants were informed of the objectives of the study, as well as how the data would be processed. Those who gave their consent to participate in the study were moved to the online questionnaire.

All of the entries were converted into an Excel spreadsheet for cleaning purposes. Incomplete surveys (no responses for the risk ranking questions) were discarded. Valid surveys were then entered into SPSS for statistical analyses. The chi square test was used for the nominal variables. The statistical significance level was set at $p<0.05$. The risk ranking was analyzed using weighted averages for each group separately.

The risk ranking by health professionals was used to create an infographic by cartoonist/illustrator Kemal Gökhan Gürses.

\section{RESULTS}

During the month of August 2020, a total of 1,992 answers to the survey were submitted. Of these answers, 1,614 were valid.

Of the 1,614 respondents, 738 (45.7\%) were health professionals, and 876 (54.3\%) were from nonhealth sectors. The age distribution of respondents varied from 18 to 93 . The mean age among health professionals was $44 \pm 12.6$, and among others 45 \pm 14.9 .

Of the 738 health sector respondents, 256 (34.7\%) were male and 482 (65.3\%) were female. The sex distribution in non-health sectors was similar with 307 male (35.0\%) and 569 female (65\%).

The majority of health professionals (58\%) were physicians.

The distribution of study participants is shown in Table 1.

The distribution of health professionals by occupation is shown in Table 2.

167 respondents $(10.3 \%)$ reported that they did not have any occupation (120 being students), while $234(14.5 \%)$ reported that they are retired. Of the 1,096 participants with an active occupation, 737 (67.2\%) indicated that they are actively going to their workplace on a daily basis, while 359 (32.8\%) indicated that they stay at home.

Concerning the current behaviors in regard to facemask use, physical distancing, handwashing and the use of disinfectant solutions, both groups reported a higher percentage of these behaviors being practiced either always or most of the time (Table 3).

The two groups' behaviors regarding the use of facemasks were found to be similar $(\times 2=5.023$; $p=0.250$ ). Similarly, two groups reported a similar 
Table 1. Distribution of study participants $(n=1,614)$

\begin{tabular}{|c|c|c|c|c|c|c|}
\hline \multirow{3}{*}{ Socio-demographic variables } & \multicolumn{4}{|c|}{ Study Population } & \multirow{2}{*}{\multicolumn{2}{|c|}{ Total }} \\
\hline & \multicolumn{2}{|c|}{ Health Sector } & \multicolumn{2}{|c|}{ Non-health Sectors } & & \\
\hline & $\mathrm{n}$ & $\%$ & $\mathrm{n}$ & $\%$ & $\mathrm{n}$ & $\%$ \\
\hline \multicolumn{7}{|l|}{ Sex } \\
\hline Female & 482 & 65.3 & 569 & 65.0 & 1051 & 64.2 \\
\hline Male & 256 & 34.7 & 307 & 35.0 & 563 & 35.8 \\
\hline \multicolumn{7}{|l|}{ Age groups (year) } \\
\hline$\leq 29$ & 124 & 16.8 & 169 & 19.3 & 293 & 18.2 \\
\hline $30-39$ & 182 & 24.7 & 147 & 16.8 & 329 & 20.4 \\
\hline $40-49$ & 172 & 23.3 & 176 & 20.1 & 348 & 21.6 \\
\hline $50-59$ & 177 & 24.0 & 220 & 25.1 & 397 & 24.6 \\
\hline $60+$ & 83 & 11.2 & 164 & 18.7 & 247 & 15.2 \\
\hline \multicolumn{7}{|l|}{ Educational level } \\
\hline Primary and secondary completed & 1 & 0.1 & 13 & 1.5 & 14 & 0.9 \\
\hline High school graduate & 26 & 3.5 & 200 & 22.8 & 226 & 14.0 \\
\hline University graduate & 494 & 67.0 & 478 & 54.6 & 972 & 60.2 \\
\hline Vocational school completed & 49 & 6.6 & 77 & 8.8 & 126 & 7.8 \\
\hline Post graduate & 168 & 22.8 & 108 & 12.3 & 276 & 17.1 \\
\hline Total & 738 & 100.0 & 876 & 100.0 & 1,614 & 100.0 \\
\hline
\end{tabular}

Table 2. Distribution of health professionals by occupation $(n=738)$

\begin{tabular}{|l|c|c|}
\hline Occupation & $\mathrm{n}$ & $\%$ \\
\hline Physician & 428 & 58.0 \\
\hline Dentist & 85 & 11.5 \\
Nurse & 75 & 10.2 \\
\hline Physiotherapist & 38 & 5.1 \\
Midwife & 19 & 2.6 \\
Pharmacist & 8 & 1.1 \\
Psychologist & 8 & 1.1 \\
Others (including missing) & 79 & 10.4 \\
\hline Total & $\mathbf{7 3 8}$ & $\mathbf{1 0 0 . 0}$ \\
\hline
\end{tabular}

practice of respecting the minimum of $1.5 \mathrm{~m}$ distance from others $(x 2=3.641 ; p=0.056)$.

Participants from the health sector wash their hands significantly more than those from nonhealth sectors $(x 2=11.822 ; p=0.004)$. It was also found that the use of hand sanitizers is significantly higher in the health sector $(x 2=16.658 ; p=0.002)$.

A total of 43 daily activities were used for risk ranking on a scale of 1 to 5. Risk ranking was evaluated for each group separately using weighted averages. Similarities were observed in the risk rankings of both groups. The final weighted averages of the risk scores were grouped as high (4.0 and above), medium (3.0 to 3.9), medium-low (2.0 to 2.9 ), and low (1.0 to 1.9$)$.

The risk ranking of everyday activities by groups is shown in Table 4.

Health professionals reported higher risk scores for 40 activities (93.0\%) compared to non-health sector respondents. However, out of the 40 activities, statistical significance was observed only in 26 (65.0\%).

Although there were no significant differences, non-health sector respondents gave high risk scores to four activities (attending a religious 
Table 3. Current behaviors in regard to facemask use, physical distancing, handwashing and the use of disinfectant solutions by health and non-health sector respondents

\begin{tabular}{|c|c|c|c|c|c|c|c|}
\hline \multirow{2}{*}{ Variables } & \multicolumn{2}{|c|}{ Health sector } & \multicolumn{2}{|c|}{ Non-health sectors } & \multicolumn{2}{|c|}{ Total } & \multirow{2}{*}{$\begin{array}{l}\text { Chi square } \\
\text { and } p \text { value }\end{array}$} \\
\hline & $\mathrm{n}$ & $\%$ & $\mathrm{n}$ & $\%$ & $\mathrm{n}$ & $\%$ & \\
\hline \multicolumn{8}{|l|}{ Facemask use } \\
\hline Always/most of the time & 719 & 97.4 & 844 & 96.3 & 1,563 & 96.8 & $x^{2}=5.023$ \\
\hline Sometimes /very seldom/never & 19 & 2.6 & 32 & 3.7 & 51 & 3.2 & $p=0.250$ \\
\hline \multicolumn{8}{|l|}{$\begin{array}{l}\text { Respecting a minimum of } 1.5 \mathrm{~m} \\
\text { distance from others }\end{array}$} \\
\hline Always/most of the time & 686 & 93.0 & 791 & 90.3 & 1,477 & 91.5 & $x^{2}=3.641$ \\
\hline Sometimes /very seldom/never & 52 & 7.0 & 85 & 9.7 & 137 & 8.5 & $p=0.056$ \\
\hline \multicolumn{8}{|l|}{ Handwashing } \\
\hline Always/most of the time & 724 & 98.1 & 833 & 95.1 & 1,557 & 96.5 & $x^{2}=11.822$ \\
\hline Sometimes /very seldom/never & 14 & 1.9 & 43 & 4.9 & 57 & 3.5 & $p=0.004$ \\
\hline \multicolumn{8}{|l|}{ Use of hand sanitizers } \\
\hline Always/most of the time & 582 & 78.9 & 644 & 73.5 & 1,226 & 76.0 & $x^{2}=16.658$ \\
\hline Sometimes/very seldom/never & 156 & 21.1 & 232 & 26.5 & 388 & 24.0 & $p=0.002$ \\
\hline Total & 738 & 100.0 & 876 & 100.0 & & & \\
\hline
\end{tabular}

service, sending kids to school, and receiving a worker from outside into your home) compared to health professionals.

When risk scores were analyzed by age, those 40 years and older tended to give higher scores compared to those 39 years and younger for 24 activities (55.8\%), Statistical significance was observed in 16 of these scores (66.7\%). These included activities like shaking hands or hugging a friend, eating in a restaurant (indoors), going to a bar or night club, and going to a movie theater. The younger age group gave higher scores for 19 activities (44.2\%) while only 3 of these (going to a hair salon or barbershop, sending kids to school, and attending demonstrations, mass protests) were statistically significant (15.8\%).

Further analysis of the risk ranking of non-health sector respondents by sex showed that women had the tendency to give higher risk scores $(p<0.01)$. Women did so for a total of $13(30 \%)$ activities. Men gave a significantly higher risk score in only one activity.

Analysis of risk ranking by education revealed that university graduates gave higher scores compared to high school and lower graduates. The scores of university graduates were significantly higher in 12 (28\%) activities.

\section{DISCUSSION}

The findings on basic non-pharmaceutical interventions (use of facemasks, respecting physical distance, handwashing and use of hand sanitizers) as well as risk ranking of everyday activities were analyzed to compare health professionals and nonhealth professionals' choices.

Group practices regarding the use of facemasks (when outside of home) and respecting a physical distance of at least $1.5 \mathrm{~m}$ were found to be similar. Handwashing and the use of hand sanitizers were significantly higher in the group of health professionals.

Although the risk ranking showed a similar trend for health professionals and non-health sector respondents, health professionals had a tendency of giving higher risk scores to the majority of daily activities. This is likely due to the fact that health professionals, compared to non-health sector respondents, are more knowledgeable about the likelihood of COVID-19 transmission under certain circumstances and its consequences.

Risk ranking of non-health sector respondents by sex indicated that women gave statistically significant higher risk scores compared to men $(p<0.01)$. Women gave significantly higher scores 
Table 4. Ranking of everyday activities by risk of coronavirus by groups (weighted averages on a scale of 1 to 5 )

\begin{tabular}{|c|c|c|c|c|}
\hline Risk & Activity & Health sector & Non health-sector & $\mathrm{p}$ value \\
\hline \multirow{21}{*}{ High } & Attending military recruit parties & 4.75 & 4.71 & 0.185 \\
\hline & Attending an engagement or wedding party & 4.74 & 4.64 & 0.002 \\
\hline & Going to a bar or night club & 4.74 & 4.68 & 0.058 \\
\hline & Shaking hands or hugging a friend & 4.69 & 4.57 & 0.001 \\
\hline & Attending a funeral & 4.66 & 4.53 & 0.001 \\
\hline & Going to a kahvehane (coffee shop) & 4.66 & 4.48 & 0.001 \\
\hline & Hosting friends for (or attending) celebrations/birthdays & 4.59 & 4.47 & 0.001 \\
\hline & Attending demonstrations, mass protests & 4.58 & 4.48 & 0.008 \\
\hline & Traveling by bus (intercity, long distance) & 4.46 & 4.34 & 0.003 \\
\hline & Taking a public bus or metro & 4.44 & 4.36 & 0.050 \\
\hline & Going to a movie theater & 4.42 & 4.36 & 0.155 \\
\hline & Attending a religious service & 4.42 & 4.47 & 0.255 \\
\hline & Going to a sports stadium & 4.41 & 4.40 & 0.811 \\
\hline & Traveling by train (intercity, long distance) & 4.39 & 4.26 & 0.003 \\
\hline & Traveling by boat (sitting inside) & 4.35 & 4.19 & 0.001 \\
\hline & Eating in a restaurant (indoors) & 4.24 & 4.09 & 0.001 \\
\hline & Sitting in a doctor's or dentist's waiting room & 4.22 & 4.07 & 0.001 \\
\hline & Working out at the gym & 4.20 & 4.17 & 0.519 \\
\hline & Sending kids to school & 4.20 & 4.24 & 0.386 \\
\hline & Traveling by plane & 4.13 & 4.07 & 0.212 \\
\hline & Playing team sports (football, volleyball, basketball) & 4.11 & 4.04 & 0.133 \\
\hline \multirow{18}{*}{ Medium } & Attending exams in a classroom or amphitheater. & 3.99 & 3.89 & 0.001 \\
\hline & Going to a hair salon or barbershop & 3.97 & 3.74 & 0.001 \\
\hline & Taking a service bus for work & 3.95 & 3.82 & 0.007 \\
\hline & Going to work at the office & 3.91 & 3.70 & 0.001 \\
\hline & Having lunch at school or the workplace & 3.91 & 3.88 & 0.524 \\
\hline & Walking in a busy downtown & 3.84 & 3.76 & 0.099 \\
\hline & Going to a local vegetable market & 3.83 & 3.68 & 0.004 \\
\hline & Having dinner at someone else's house & 3.64 & 3.33 & 0.001 \\
\hline & Receiving a worker into your home (cleaning or baby care) & 3.61 & 3.63 & 0.687 \\
\hline & Staying at a hotel for a night & 3.46 & 3.45 & 0.852 \\
\hline & Attending a backyard barbecue & 3.42 & 3.30 & 0.026 \\
\hline & Taking a taxi & 3.41 & 3.33 & 0.107 \\
\hline & Going to a supermarket & 3.38 & 3.12 & 0.001 \\
\hline & Going for a run with others & 3.32 & 3.09 & 0.001 \\
\hline & Going to the beach & 3.31 & 3.18 & 0.022 \\
\hline & Going to a kiosk & 3.06 & 2.84 & 0.001 \\
\hline & Going for a walk with others & 3.02 & 2.85 & 0.001 \\
\hline & Getting takeout from a restaurant & 3.01 & 2.98 & 0.574 \\
\hline \multirow{4}{*}{ Medium-low } & Receiving packages from couriers and online deliveries & 2.94 & 2.78 & 0.003 \\
\hline & Eating in a restaurant (outside) & 2.85 & 2.71 & 0.003 \\
\hline & Traveling by boat (sitting outside) & 2.74 & 2.65 & 0.059 \\
\hline & Getting gasoline & 2.14 & 2.04 & 0.027 \\
\hline
\end{tabular}

Bold highlighted $\mathrm{p}$ values correspond to activities that are ranked with a significantly higher risk score by health professionals. 
for a total of $13(30 \%)$ activities, while men gave a significantly higher risk score for only one activity. This finding is in line with the assumption that women consider risks to be more serious and more problematic than men $[18,19]$. It was also found that university graduates gave higher scores compared to high school and lower graduates. The scores of university graduates were significantly higher in 12 (28\%) activities. Similarly, the older age group generally gave higher scores to compared to the younger age group. These findings are also in line with general trends $[18,19]$.

The activities that were ranked as high-risk (e.g., attending a religious service, going to a bar or night club, attending a wedding, traveling by bus) share some common features like closed spaces, crowded places, and the need for people to be close to each other or even touching.

The handling of the pandemic by the MoH in Turkey and especially its risk communication were heavily criticized by professional medical societies such as the Turkish Medical Association. A common criticism is that the government was never transparent in communicating COVID-19 information and its related risks. Although the ministry introduced an application (HES) for people to see risky regions on their smart phones, differentiated by a color code (but no other information), it cannot justify the lack of communication of the details on case distribution by location and age groups. Furthermore, members of the COVID-19 Scientific Committee to the $\mathrm{MoH}$ mentioned that they were also not informed on local case distribution and other epidemiological parameters [31]. Therefore, it is assumed that risk communication about preventive actions by the $\mathrm{MoH}$ was formulated based on global assumptions, and never tailored to local realities. This also manifested itself in non-pharmaceutical control measures introduced by the government - a curfew (during weekdays from 21:00 to 05:00 and weekends from Friday 21:00 to Monday 05:00) was introduced with no explanation for what kind of transmission risks it would address [32].

Risk communication is expected to be shaped by social studies conducted in communities. However, the only risk perception survey conducted in Turkey was in March 2020 following the declaration of the first COVID-19 case [28]. Although the survey revealed that $12 \%$ of the 824 participants were not taking any precautions at all and 22\% did not hesitate to go anywhere, the survey not being repeated in the following months prevented valuable information from being incorporated into risk communication. The authors speculate that the MoH's displayed management style of only involving governmental structures and not appreciating a 'whole-of-society' approach would have prevented such information from being strategically utilized [33-36]. Messages for the population mainly relied on Minister's tweets or press releases, and mostly telling what needs to be done rather why and how needs to be done without any visuals.

The responses from health professionals were used to create an infographic to illustrate the risk levels of the selected 43 everyday activities from a COVID-19 transmission perspective (Figure 1). As mentioned before, infographics made about the coronavirus often use bar or bubble graphs and color coding to illustrate risk levels $[26,27]$. Some use icons to add visuals [27]. The research team evaluated some of these infographics as difficult to read and interpret. For example, the risk ranking by Texas Medical Association shows the flow from low to high risk by illustrating it from top to bottom and from right to left graphically, and an infographic by Information is Beautiful uses dark backgrounds that make reading the details challenging $[37,38]$. It was also notable that when such infographics had around 40 activities, people would be likely to check only the lowest and highest risk levels, then browse through the rest quickly. To eliminate graphical challenges for readers, we decided to take a different approach in constructing our infographic and chose to work with a renowned cartoonist/ illustrator, Kemal Gökhan Gürses. Our infographic, an illustration of Istanbul, shows the 43 activities from our survey, ranked by health professionals, colored in red (high risk), yellow (medium), and green (low) with additional annotations detailing the activity and its risk level out of 5 . A special warning was posted to remind the public that the risk of transmission of COVID-19 increases with five conditions: closed spaces, crowded places, close-contact settings, long duration of the activity, and forceful exhalations (e.g. sneezing, yelling, singing, and coughing) $[39,40]$. The illustration has also been used in an interactive web application, allowing users to explore the different risk scores attributed to the 43 activities [41]. 
Authors believe the importance of visuals including cartoon style illustrations in conveying messages to the general public.

\section{LIMITATIONS}

This study had certain limitations. Since the survey link was disseminated through social media and personal channels, it could have led to biases in terms of the participating demographics. Although additional channels like professional societies' mailing lists were used, it does not eliminate the potential bias. Online surveys naturally prohibit certain types of people from participating such as those who do not have internet access. The lack of random sampling may also have led to questionable (if any) statistical confidence and margin of error.

\section{ACKNOWLEDGEMENTS}

The authors thank Kemal Gökhan Gürses for his excellent work on the infographic. The authors also thank the Istanbul Family Physicians Association (ISTAHED) and the Turkish Physiotherapists Association for the distribution of the survey link to their members and follow-up.

\section{CONFLICT Of INTEREST STATEMENT}

The authors declare that they have no known competing financial interests or personal relationships that could have appeared to influence the work reported in this paper. 


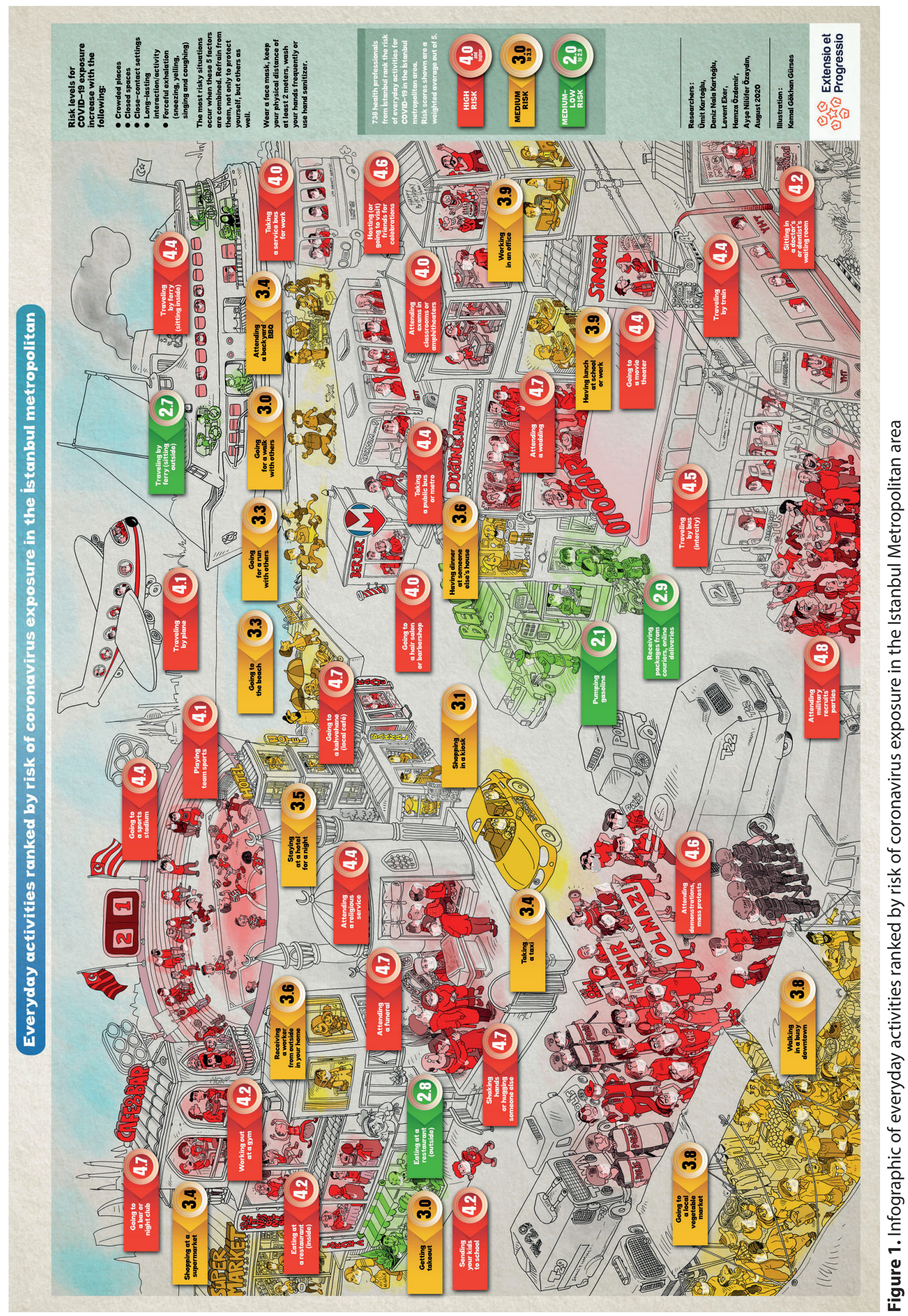


[1] World Health Organization. Novel Coronavirus (2019nCoV) Situation Report-1, 21 January 2020. Geneva. Available from: https://www.who.int/docs/default-source/ coronaviruse/situation-reports/20200121-sitrep-1-2019ncov.pdf?sfvrsn=20a99c10_4 (accessed 30 November 2020)

[2] World Health Organization. WHO Director-General's opening remarks at the media briefing on COVID-19. 11 March 2020. Geneva. Available from: https://www. who.int/director-general/speeches/detail/who-directorgeneral-s-opening-remarks-at-the-media-briefing-oncovid-19---11-march-2020 (accessed 28 November 2020)

[3] World Health Organization. Available from: https:// twitter.com/who/status/1237776967526764544?lang=en (accessed 28 November 2020)

[4] European Centre for Disease Prevention and Control. Guidelines for the implementation of non-pharmaceutical interventions against COVID-19. 12 September 2020, Technical Report. https://www.ecdc.europa.eu/sites/ default/files/documents/covid-19-guidelines-nonpharmaceutical-interventions-september-2020.pdf (accessed 26 November 2020)

[5] World Health Organization. Considerations in the investigation of cases and clusters of COVID-19, Interim Guidance, 22 October 2020. Geneva. Available from: https://www.who.int/publications/i/item/considerationsin-the-investigation-of-cases-and-clusters-of-covid-19 (accessed 30 November 2020)

[6] World Health Organization. Contact tracing in the context of COVID-19. Interim Guidance 10 May 2020. Geneva. Available from: https://apps.who.int/iris/bitstream/ handle/10665/332049/WHO-2019-nCoV-Contact_ Tracing-2020.1-eng.pdf? sequence $=1$ \&isAllowed $=y$ (accessed 2 December 2020)

[7] Flaxman S, Mishra S, Gandy A, et al. Estimating the effects of non-pharmaceutical interventions on COVID-19 in Europe. Nature 2020; 584: 257-261. https://doi. org/10.1038/s41586-020-2405-7

[8] Davies NG, Kucharski A, Eggo R, Et al. Effects of nonpharmaceutical interventions on COVID-19 cases, deaths, and demand for hospital services in the UK: a modelling study. Lancet Public Health 2020; 5: e375-385. https://doi. org/10.1016/S2468-2667(20)30133-X

[9] World Health Organization. WHO Director-General's opening remarks at the media briefing on COVID-19. 13 April 2020. Geneva. Available from: https://www.who.int/ director-general/speeches/detail/who-director-generals-opening-remarks-at-the-media-briefing-on-covid-19-13-april-2020 (accessed 18 November 2020)

[10] M. Reston. Pressure mounts on governors to ease restrictions. CNN Politics. 3 May 2020. Available from: https://edition.cnn.com/2020/05/03/politics/pressuregovernors-restrictions/index.html (accessed 11 November 2020)
[11] World Health Organization. Coronavirus Disease (COVID-19) Dashboard. Geneva. Available from: https:// covid19.who.int/ (accessed 7 June 2020)

[12] The Guardian. Turkey announces its first case of coronavirus. 11 March 2020. Available from: https://www. theguardian.com/world/2020/mar/11/turkey-announcesits-first-case-of-coronavirus (accessed 10 November 2020)

[13] Ministry of Health. Ankara: COVID-19 Information Page. Available from: from https://covid19.saglik.gov.tr/TR66935/genel-koronavirus-tablosu.html (accessed 7 June 2021)

[14] Turkish Medical Association. COVID-19 Pandemisi Altinci Ay Degerlendirme Raporu (COVID-19 Pandemic - 6th month evaluation report). 17 September 2020. Ankara. Available from: https://www.ttb.org.tr/kutuphane/ covid19-rapor_6.pdf (accessed 12 November 2020)

[15] Bayram H, Kokturk N, Elbek O, et al. Interference in scientific research on COVID-19 in Tukey. The Lancet 2020; 396(10249): 463-464. https://doi.org/10.1016/S01406736(20)31691-3

[16] htt p s: / / witter.com/drfahrettinkoca / status/1319349956474437634 [internet]

[17] Park KF, Shapira Z. Risk and Uncertainty. In: Augier M., Teece D (eds). The Palgrave Encyclopedia of Strategic Management. London; Palgrave Macmillan, 2017: https:// doi.org/10.1057/978-1-349-94848-2_250-1. Available from: https://link.springer.com/content/pdf/10.1057\% 2F978-1-349-94848-2_250-1.pdf (accessed 10 October 2020)

[18] Strong C, Ansons T. Responding to COVID-19: The importance of understanding how we evaluate risk. March 2020. Available from: https://www.ipsos.com/sites/ default/files/cp/about_us/documents/2020-09/covid-19risk-perception.pdf (accessed 9 October 2020)

[19] Slovic P. Perception of risk. Science 1987 April 17; 236: 280285. https://doi.org/10.1126/science.3563507

[20] Slovic P, Weber EU. Perception of risk posed by extreme events (conference background paper) “Risk Management strategies in an Uncertain World". Palisades; New York, 1213 April 2020. Available from: https://www.Ideo.columbia. edu/chrr/documents/meetings/roundtable/white_ papers/slovic_wp.pdf (accessed 9 April 2021)

[21] Garcia-Alamino J. Human biases and the SARS-CoV-2 pandemic. Intensive Crit Care Nurs; 2020; 58: 102861. https://doi.org/10.1016/j.iccn.2020.102861

[22] Jurkowitz M, Mitchell A, Shearer E, et al. U.S. Media Polarization and the 2020 Election: A Nation Divided. 2020. Available from : https://www.journalism.org/wpcontent/uploads/sites/8/2020/01/PJ_2020.01.24_MediaPolarization_FINAL.pdf (accessed 7 May 2020)

[23] Slovic P. "Trust, Emotion, Sex, Politics, and Science: Surveying the Risk Assessment Battlefield," University of Chicago Legal Forum 1997(1): Article 4. Available at: http://chicagounbound.uchicago.edu/uclf/vol1997/iss1/4 
[24] Khosravi M. Perceived risk of COVID-19 pandemic: The role of public worry and trust. Electron J Gen Med 2020. 17(4):em203. https://doi.org/10.29333/ejgm/7856

[25] Kartoglu U. Quality Risk Management Mental Modelling: examples of exposure in everyday life, EPELA, Geneva, 2017. http://kartoglu.ch/qualityriskmanagement/

[26] COVID-19 risk chart divides low and high-risk activities. FoxNews. 9 July 2020. Available from: https://www. fox 21 news.com/digital-now/covid-19-risk-chart-divideslow-and-high-risk-activities/ (accessed 27 October 2020)

[27] COVID-19 Recovery Consulting. COVID-19 Activity Risk Index. 8 July 2020. Available from: https://www. covid19reopen.com/resources/covid-19-daily-activityrisk-index (accessed 19 October 2020)

[28] Turkiye'de yuzde $12^{\prime}$ lik kesim koronoviruse karsi hicbir onlem almiyor ( $12 \%$ of the population does not take any measures against coronavirus). 20 March 2020. Available from: https://www.haberler.com/toplumun-12-sicovid19-dan-korkmuyor-13035251-haberi/ (accessed 20 September 2020)

[29] Ekiz T, Iliman E, Donmez E. Bireylerin saglik anksiyetesi duzeyleri ile COVID-19 salgini kontrol algisinin karsilastirilmasi (Comparison of health anxiety level and control perception of COVID-19). IJHMSR 2020; 6(1): 139154. Available from: https://dergipark.org.tr/tr/download/ article-file/1077630

[30] Saglik Bakanligi toplumun koronovirus algisini olcecek (Ministry of Health to measure public perception of coronavirus) 25 June 2020. Available from: https://www. aa.com.tr/tr/koronavirus/saglik-bakanligi-toplumunkoronavirus-algisini-olcecek/1889300 (accessed 27 September 2020)

[31] Bilim Kurulu uyesi: Gercek vaka sayilari bize de verilmiyor (Scientific Committee member: Number of cases are also not shared with us). Dokuz8 Haber. 17 November 2020. Available from: https://dokuz8haber.net/gundem/bilimkurulu-uyesi-gercek-vaka-sayilari-bize-de-verilmiyor/ (accessed 29 December 2020)

[32] Ortayli N. Hafta sonu sokaga cikma yasaklari ne kadar etkili (How effective are the weekend curfews). Yetkin Report 15 May 2020. Available from: https://yetkinreport. com/2020/05/15/hafta-sonu-sokaga-cikma-yasaklari-nekadar-etkili/ (accessed 11 December 2020)
[33] The whole of society Approach - Levels of engagement and meaningful participation of different stakeholders in the review process of the 2030 Agenda. SDG Help Desk. Available from: http://sdghelpdesk.unescap.org/elibrary/whole-society-approach-levels-engagement-andmeaningful-participation-different (accessed 11 January 2021)

[34] World Health Organization. COVID-19: WHO calls for a stronger role of society approach in South-East Asia region. Geneva. 3 April 2020. Available from: http://sdghelpdesk. unescap.org/e-library/whole-society-approach-levelsengagement-and-meaningful-participation-different (accessed 17 November 2020)

[35] Association for Progressive Communications. Voice: The whole-of-society approach to the COVID-19 pandemic. 20 April 2020. Available from: https://www.apc.org/en/ news/voice-whole-society-approach-covid-19-pandemic (accessed 9 October 2020)

[36] Hui TM. Living with uncertainty: A whole-of-society approach to pandemics, Policy report July 2020. Nanyang Technological University, Singapore. Available from: https://www.rsis.edu.sg/wp-content/uploads/2020/07/ PR200717_Living-With-Uncertainty.pdf (accessed 9 November 2020)

[37] Knowyour riskduring COVID-19.Texas Medical Association, Dallas, TX https://www.texmed.org/TexasMedicineDetail. aspx?id=53977 (accessed 9 November 2020)

[38] Coronavirus riskiest activities. Information is beautiful. https://informationisbeautiful.net/visualizations/covid19-coronavirus-infographic-datapack/ (accessed 9 November 2020)

[39] Tufekci Z. We need to talk about ventilation. The Atlantic. 30 July 2020. Available from: https://www.theatlantic. com/health/archive/2020/07/why-arent-we-talkingmore-about-airborne-transmission/614737/ (accessed 15 November 2020)

[40] Tufekci Z. This overlooked variable is the key to the pandemic. It's not R. The Atlantic. 30 September 2020. Available from: https://www.theatlantic.com/health/ archive/2020/09/k-overlooked-variable-drivingpandemic/616548/ (accessed 12 November 2020)

[41] Everyday activities ranked by risk of coronavirus exposure in the Istanbul Metropolitan Area. https://kartoglu.ch/ riskmap/ (accessed 4 January 2021) 